\title{
One-dimensional Simulation of Alternating Conduction Under Hyperkalaemic Conditions
}

\author{
Jiaqi Liu ${ }^{1}$, Yuan $\mathrm{Gao}^{1}$, Yinglan Gong ${ }^{1}$, Ling Xia ${ }^{1}$, Wenlong $\mathrm{Xu}^{2}$, Mingfeng Jiang ${ }^{3}$, Gangmin Ning ${ }^{1}$ \\ ${ }^{1}$ Department of Biomedical Engineering, Zhejiang University, Hangzhou 310027, China \\ ${ }^{2}$ China Jiliang University, Hangzhou 310018, China \\ ${ }^{3}$ Zhejiang Sci-Tech University, Hangzhou 310018, China
}

\begin{abstract}
Hyperkalaemic conditions belonged to one of changes brought by ischemia. Hyperkalaemia is identified as a major determinant of ventricular arrhythmias. Onedimensional fiber model of transmural cells was used to simulate regional hyperkalaemic conditions. We investigated the process of alternating conduction developing induced by hyperkalaemia. Hyperkalaemic region closer to Endo cells was more likely to cause 2:1 conduction blocks. Increased depolarization time and conduction delay were essential for blocks developing. The L-type calcium current $\left(I_{\text {CaL }}\right)$ became too small to maintain the phase of depolarization every other beat during the process of conduction. Alternans associated with alternating conduction could be considered as a marker of acute regional ischemia/hyperkalaemia.
\end{abstract}

\section{Introduction}

Myocardial ischemia is associated with hyperkalaemia, acidosis and anoxia [1,2]. A large $\left[\mathrm{K}^{+}\right]_{\mathrm{o}}$ gradient plays a key role in the development of the arrhythmogenic substrate in human ischemic hearts $[3,4,5]$. Lots of studies have investigated mechanistic links between hyperkalaemia/ischemia and arrhythmias [2,5,6]. Onedimensional fiber model was used to simulate regional hyperkalaemic conditions. These results could shed light on the more detailed mechanism of arrhythmias occurring under hyperkalaemic/ischemic conditions in human hearts. Previous studies don t link blocks with the location of hyperkalaemic zone and we compared the effects of different hyperkalaemic zone on blocks developing. Moreover, earlier studies show that the L-type calcium current plays an important role in the alternating blocks $[2,6]$. But they don't give the direct cause of the little availability of this current. Here we investigated links between the availability of the current and conduction delay originating from hyperkalaemic conditions. Our results also confirm that alternans accompanied with alternating conduction can serve as a maker of acute regional ischemia/hyperkalaemia [2,5,6,7].

\section{Methods}

\subsection{One-dimensional fiber model}

The fiber was constructed by human ventricular transmural cell model [8]. $\mathrm{G}_{\mathrm{ks}}$ in the endocardial cell model was set to $0.149 \mathrm{nS} / \mathrm{pF}$ based on the experimental observations [9]. This fiber consisted of 60 endocardial (Endo) cells, 45 midmyocardial (M) cells and 60 epicardial (Epi) cells. The length of each cell is $0.01 \mathrm{~cm}$.

The diffusion coefficient was described in terms of $\mathrm{D}$, which characterizing electrical wave spread between cells through gap junctional coupling [10]. Here we set the value of $\mathrm{D}$ to be $0.154 \mathrm{~mm}^{2} / \mathrm{ms}$. That corresponded to the conduction velocity of $70 \mathrm{~cm}^{2} / \mathrm{ms}[11] . \mathrm{V}_{\mathrm{m}}, \mathrm{C}_{\mathrm{m}}$ were transmembrane potential and membrane capacity respectively. $\mathrm{I}_{\text {tot }}$ represented the total currents of ionic current and simulation current. The electrical propagation in the fiber was expressed by the following equation.

$$
\begin{aligned}
& \frac{\partial V_{m}}{\partial t}=-\frac{I_{\text {tot }}}{C_{m}}+D \cdot \nabla^{2} V_{m} \\
& I_{\text {tot }}=I_{\text {ion }}+I_{\text {stim }}
\end{aligned}
$$

\subsection{Hyperkalaemia simulation}

Regional hyperkalaemic conditions were simulated by increasing extracellular potassium concentration of cells in the fiber. Cycle length was applied at 390ms.

1. Hyperkalaemia simulation of M cells: $M$ cells from the $86^{\text {th }}$ to $95^{\text {th }}$ were set under hyperkalaemic conditions. $\left[\mathrm{K}^{+}\right]_{\mathrm{o}}$ value was increased by $1 \mathrm{mM}$ from $6 \mathrm{mM}$ to $11 \mathrm{mM}$.

2. Hyperkalaemia simulation of Epi cells: Epi cells from the $156^{\text {th }}$ to $165^{\text {th }}$ were set with $\left[\mathrm{K}^{+}\right]_{0}$ of $11 \mathrm{mM}$.

3. The above ten Epi cells were replaced by $\mathrm{M}$ cells under hyperkalaemic conditions with $\left[\mathrm{K}^{+}\right]_{0}=11 \mathrm{mM}$. Other cells remained unchanged.

\section{Results}

High $\left[\mathrm{K}^{+}\right]_{0}$ leads to elevated resting membrane potential (RMP) [12] and slowing conduction [5]. As Figure $1 \mathrm{~A}$ showed, the resting membrane potential (RMP) of the $\mathrm{M}$ cell became less negative under hyperkalaemic conditions. The time that the M cell taking to reach APA became longer as the $\left[\mathrm{K}^{+}\right]_{0}$ level increased (Figure 1D). 
Alternating blocks occurred as $\left[\mathrm{K}^{+}\right]_{\mathrm{o}}$ values of these $\mathrm{M}$ cells (from the $86^{\text {th }}$ to $95^{\text {th }}$ cell) were increased to $11 \mathrm{mM}$. APA of each cell along the fiber decreased gradually during even beats (Figure 1C). Moreover, last Epi cells couldn't respond to the even stimuli. The current, $\mathrm{I}_{\mathrm{CaL}}$ of the $\mathrm{M}$ cell became very small during these beats (Figure 1E). Endo cells also displayed correspondingly shorter action potentials. Consecutive APs suggested that no alternans developed in the single $\mathrm{M}$ cell under hyperkalaemic conditions (Figure 1B).

Alternating blocks as well as action potential duration alternans in Endo cells disappeared while Epi cells (from the $156^{\text {th }}$ to $165^{\text {th }}$ cell) were set under hyperkalaemic conditions and other cells were in normal conditions (Figure 2A). Consecutive APs of the single Epi cell also showed no alternans with $\left[\mathrm{K}^{+}\right]_{0}$ of $11 \mathrm{mM}$ (Figure $2 \mathrm{~B}$ ).

After replacing Epi cells from $156^{\text {th }}$ to $165^{\text {th }}$ with $\mathrm{M}$ cells under hyperkalaemic conditions and maintaining other cells unchanged, we didn't yet observe alternating blocks (Figure 3).
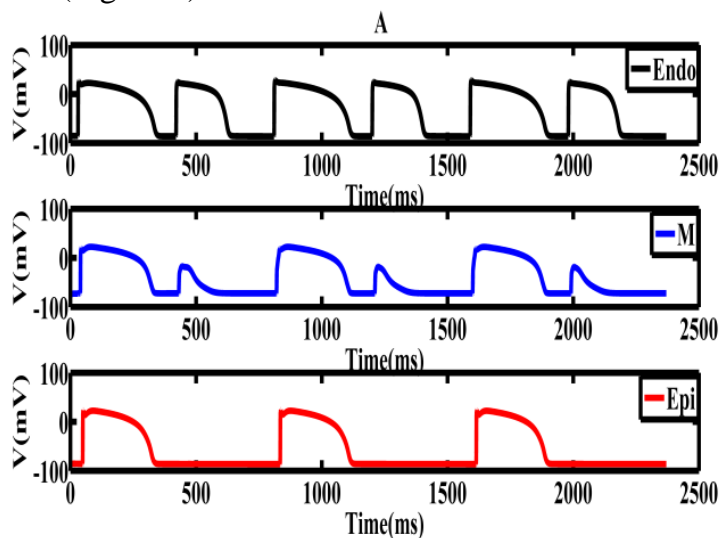

B
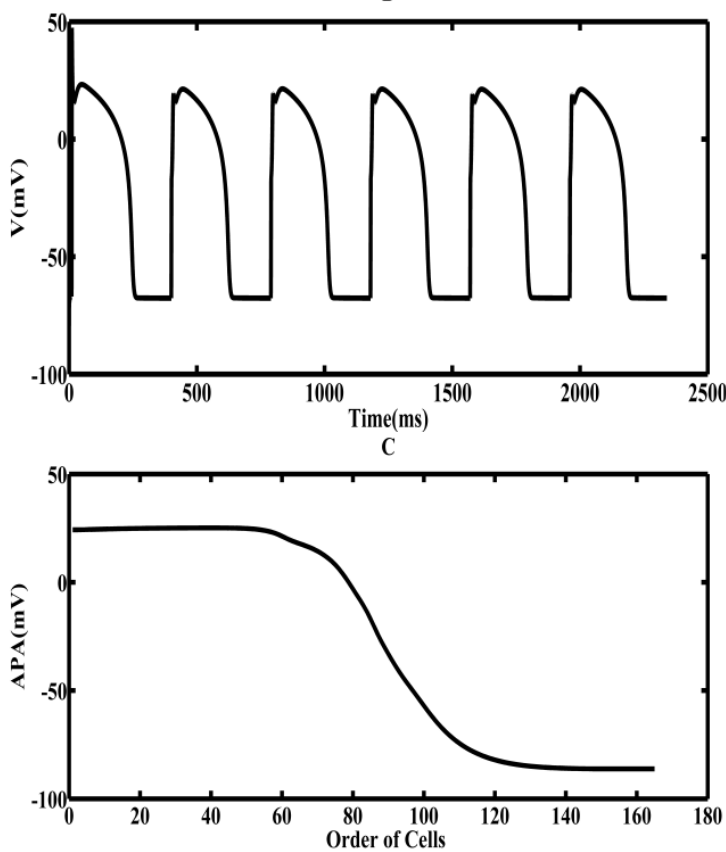
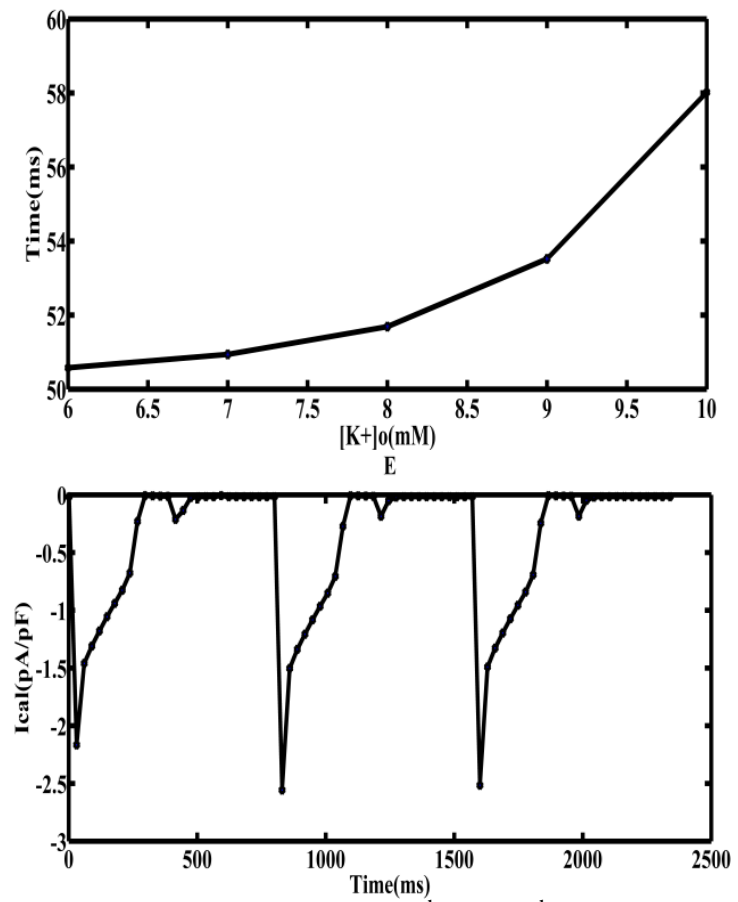

Figure 1. M cells (from the $86^{\text {th }}$ to $95^{\text {th }}$ cell) were set under hyperkalaemic conditions. A: Action potential recordings of the Endo (the $10^{\text {th }}$ ), $\mathrm{M}$ (the $85^{\text {th }}$ ) and Epi (the $155^{\text {th }}$ ) cells in the simulated $1 \mathrm{D}$ fiber with $\left[\mathrm{K}^{+}\right]_{0}$ of $11 \mathrm{mM}$. B: Action potential recordings when pacing the single $M$ cell with $\left[\mathrm{K}^{+}\right]_{0}=11 \mathrm{mM}$. C: Action potential amplitude (APA) of every cell in the fiber with $\left[\mathrm{K}^{+}\right]_{0}=11 \mathrm{mM}$. D: The time that the $95^{\text {th }}$ cell needed to reach the APA as the fiber was paced during the second beat under different $\left[\mathrm{K}^{+}\right]_{\mathrm{o}}$ values. E. The L-type calcium current $\left(\mathrm{I}_{\mathrm{CaL}}\right)$ of the $95^{\text {th }}$ cell with $\left[\mathrm{K}^{+}\right]_{0}$ of $11 \mathrm{mM}$. The value was calculated once within every $30 \mathrm{~ms}$.
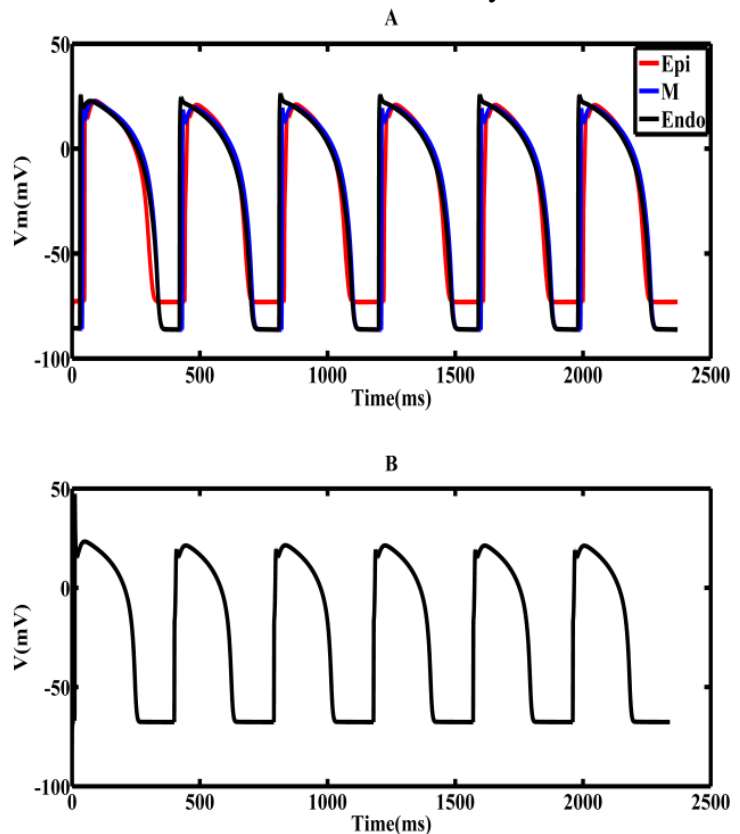
Figure 2. Epi cells (from the $156^{\text {th }}$ to $165^{\text {th }}$ cell) were set under hyperkalaemic conditions. A: Action potential recordings of the Endo (the $10^{\text {th }}$ ), $\mathrm{M}$ (the $85^{\text {th }}$ ) and Epi (the $155^{\text {th }}$ ) cells in the simulated $1 \mathrm{D}$ fiber with $\left[\mathrm{K}^{+}\right]_{0}$ of $11 \mathrm{mM}$. B: Action potential recordings when pacing the single Epi cell with $\left[\mathrm{K}^{+}\right]_{0}=11 \mathrm{mM}$.

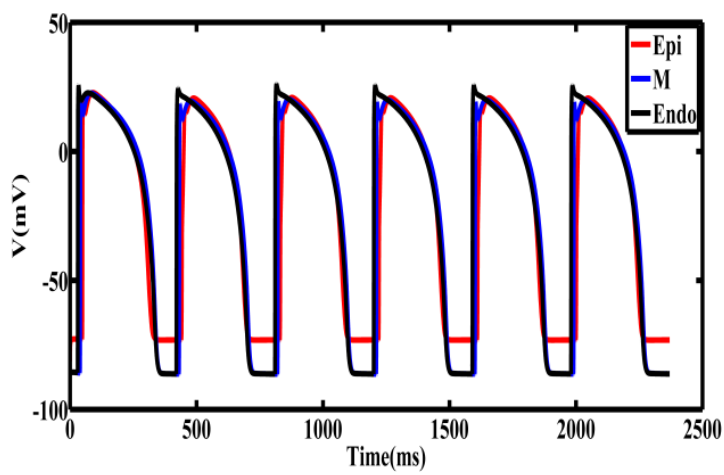

Figure 3. Action potential recordings of the Endo (the $10^{\text {th }}$ ), $M$ (the $85^{\text {th }}$ ) and Epi (the $155^{\text {th }}$ ) cells in the simulated 1D fiber. Epi cells from $156^{\text {th }}$ to $165^{\text {th }}$ were replaced by $\mathrm{M}$ cells and set under hyperkalaemic conditions with $\left[\mathrm{K}^{+}\right]_{0}=11 \mathrm{mM}$.

\section{Discussion}

2:1 conduction blocks occurred as a result of hyperkalemia in Figure 1A. However, hyperkalaemia occurring in the $156^{\text {th }}$ to $165^{\text {th }}$ cells couldn't lead to blocks whatever the cell type was (Figure 2A and Figure 3). We conclude from the above results that the development of 2:1 conduction blocks is related to the location of hyperkalaemic zone. Hyperkalaemia can increase susceptibility to blocks when the zone was closer to Endo cells.

Conduction slows under hyperkalaemic/ischemic conditions [5,13]. That result is consistent with our simulation (Figure 1D). Hyperkalaemic cells demand larger stimulus currents to make sure APs propagate along the fiber [5]. In our simulation, stimulus time increased with stimulus currents unchanged, thus resulting in depolarization time increasing and conduction delay. $\mathrm{I}_{\mathrm{CaL}}$ can be the factor translating conduction delay to block. Voltage-dependent $\mathrm{I}_{\mathrm{CaL}}$ current would need longer time to recover due to the longer duration of depolarization. As a result, the current recovered completely every other beat under hyperkalaemic conditions. And the current was too small to maintain normal depolarization during even beats. Blocks occurred as $\left[\mathrm{K}^{+}\right]_{0}$ level increased to $11 \mathrm{mM}$ in this way. Previous studies $[2,6]$ point out the important effect of $\mathrm{I}_{\mathrm{CaL}}$ on blocks, but yet they don't explain how it associates with conduction delay under hyperkalaemic conditions. In addition, $\mathrm{I}_{\mathrm{CaL}}$ plays an important role in alternans occurring in the single cell under hyperkalaemic conditions [14].

Hyperkalaemic cells interact with adjacent normal cells. Previous studies $[2,6]$ report that the area of block is like a current sink draining currents to shorten action potential durations of adjacent normal cells. In our simulation, long-short-APD alternans developed in the Endo cell of the 1D fiber with 2:1 blocks (Figure 1A). The onset of short action potential durations coincided in time with blocks occurring in $\mathrm{M}$ and Epi cells. That was, both of them occurred during even beats. Our simulation is in agreement with the earlier conclusion. Moreover, there existed no abrupt transition in action potential duration between cells [15]. The APA decreased gradually from the border zone to hyperkalaemic zone (Figure 1C). Our simulations confirm that alternans in Endo cells develop through coupling with hyperkalaemic cells. Also, alternans can be linked with conduction abnormalities [2,6].

Transmural heterogeneity induced by a large $\left[\mathrm{K}^{+}\right]_{\text {o }}$ gradient favors the occurrence of $1 \mathrm{a}$ arrhythmias in acute ischemic hearts [16]. Alternans onset accompanies with alternating blocks under regional hyperkalaemic conditions and serve as a predictor of cardiac arrhythmia $[2,5,6,7]$. This is consistent with our results. Note that after a period of myocardial ischemia, $\left[\mathrm{K}^{+}\right]_{\mathrm{o}}$ gradient will decrease $[3,4]$ and alternans may disappear. Alternans can therefore serve as a marker of early stage of myocardial ischemia/hyperkalaemia.

Although our simulations provide a new perspective of the relationship between the location of hyperkalaemia and blocks occurring, these conclusions still need further verification in 2-D and 3-D simulations. Simulation results will have a difference as the number of cells coupling with hyperkalaemic zone increases. The change of the diffusion coefficient under hyperkalaemic conditions should be considered in 3-D simulations to obtain more accurate conclusions. Thus these conclusions will be of more value in clinical practice.

\section{References}

[1] Shaw RM, Rudy Y. Electrophysiologic Effects of Acute Myocardial Ischemia A Mechanistic Investigation of Action Potential Conduction and Conduction Failure. Circulation Research 1997,80: 124-138.

[2] Bernus O, Zemlin CW, Zaritsky RM, Mironov SF, Pertsov AM. Alternating conduction in the ischaemic border zone as precursor of reentrant arrhythmias: a simulation study. Europace 2005,7: S93-S104.

[3] Coronel R, Wilms-Schopman FJ, Dekker LR, Janse MJ. Heterogeneities in $[\mathrm{K}+] \mathrm{o}$ and TQ potential and the inducibility of ventricular fibrillation during acute regional ischemia in the isolated perfused porcine heart. Circulation 1995,92: 120-129.

[4] Martišienè I, Jurevičius J, Vosyliutė R, Navalinskas A, Treinys R, et al. Alternans in Rabbit Heart During Acute 
Regional Ischemia: Optical Mapping and Microelectrode Recordings. Biophysical Journal 2014,106: 122a.

[5] Carro J, Rodríguez JF, Laguna P, Payee E. A human ventricular cell model for investigation of cardiac arrhythmias under hyperkalaemic conditions. Philosophical Transactions of the Royal Society of London A: Mathematical, Physical and Engineering Sciences 2011,369: 4205-4232.

[6] Martišienė I, Jurevičius J, Vosyliūtė R, Navalinskas A, Treinys R, et al. Evolution of action potential alternans in rabbit heart during acute regional ischemia. BioMed research international 2015.

[7] Verrier RL, Klingenheben T, Malik M, El-Sherif N, Exner DV, et al. Microvolt T-wave alternans: physiological basis, methods of measurement, and clinical utility-consensus guideline by International Society for Holter and Noninvasive Electrocardiology. Journal of the American College of Cardiology 2011,58: 1309-1324.

[8] Ten Tusscher K, Noble D, Noble P, Panfilov A. A model for human ventricular tissue. American Journal of Physiology-Heart and Circulatory Physiology 2004,286: H1573-H1589.

[9] Zhang H, Hancox JC. In silico study of action potential and QT interval shortening due to loss of inactivation of the cardiac rapid delayed rectifier potassium current. Biochemical and biophysical research communications 2004,322: 693-699.

[10] Aslanidi OV, Stewart P, Boyett MR, Zhang H. Optimal velocity and safety of discontinuous conduction through the heterogeneous Purkinje-ventricular junction. Biophysical Journal 2009,97: 20-39.
[11] Taggart P, Sutton PM, Opthof T, Coronel R, Trimlett R, et al. Inhomogeneous transmural conduction during early ischaemia in patients with coronary artery disease. Journal of molecular and cellular cardiology 2000,32: 621-630.

[12] Campese VM, Adenuga G. Electrophysiological and clinical consequences of hyperkalemia. Kidney International Supplements 2016,6: 16-19.

[13] Di Diego JM, Antzelevitch C. Acute myocardial ischemia: cellular mechanisms underlying ST segment elevation. Journal of electrocardiology 2014,47: 486-490.

[14]Liu J, Gong Y, Xia L, Zhao X. In silico investigation into cellular mechanisms of cardiac alternans in myocardial ischemia. Computational and Mathematical Methods in Medicine 2016.

[15] Janse MJ, Van Capelle F, Morsink H, Kléber AG, WilmsSchopman F, et al. Flow of" injury" current and patterns of excitation during early ventricular arrhythmias in acute regional myocardial ischemia in isolated porcine and canine hearts. Evidence for two different arrhythmogenic mechanisms. Circulation Research 1980,47: 151-165.

[16] Coronel R, Wilms-Schopman FJ. Origin of ischemiainduced phase $1 \mathrm{~b}$ ventricular arrhythmias in pig hearts. Journal of the American College of Cardiology 2002,39: 166-176.

Ling Xia

Department of Biomedical Engineering, Zhejiang University, Hangzhou 310027, China

xialing@zju.edu.cn 